Literatura y Lingüística $\mathrm{N}^{\circ} 25$

ISSN 0716-5811 / pp. 83-98

\title{
Indefinición sexual y disciplinamiento de un personaje Equis*
}

Juan D. Cid Hidalgo ${ }^{* *}$

\section{Resumen}

A través de su relación con variados tipos femeninos, Equis, personaje memorable de La nave de los locos de Cristina Peri Rossi, se suma al juego de la indefinición sexual c omo parte de la justificación de su ser/estar en el mundo. De este modo cobra suma importancia la escena del club de streaptease en que Lucía/Dolores deviene en "hermoso efebo", transformación que pone al andrógino en el centro mismo de la desarticulación y superación del binarismo fundamental hombre/mujer.

Palabras clave: andrógino, disciplina, indefinición sexual, Peri Rossi, perturbador, poder, saber.

\section{Sexual indefinition and discipline over a character X}

\begin{abstract}
Through her relationship with various female types, Equis, unforgettable character from La nave de los locos by Cristina Peri Rossi, adds herself to the play of sexual indefinition as part of justifing her being in the world. Thus, it is absolutely important the striptease club scene, where Lucía/Dolores becomes a "beautiful ephebe", transformation that sets the androgyny in the very center of dismantling and overcoming from essential binarism male/female.
\end{abstract}

Keywords: androgyny, discipline, sexual indefinition, Peri Rossi, disturbing, power, knowledge.

Recibido: 27-09-2011 Aceptado: 29-12-2011

* Investigación que forma parte del Proyecto FONDECYT No 3100007: Novela, Filantropía y saber. Ficcionalizaciones de la locura en Latinoamérica.

** Doctor en Literatura Latinoamericana. Departamento de Español, Facultad de Humanidades y Arte. Universidad de Concepción. jdcid@udec.cl 
A cuarenta años de su exilio en Barcelona', Cristina Peri Rossi (1941) sigue sorprendiendo a sus lectores y solidificando un trabajo sin igual con aquellas dimensiones intersticiales del hombre contemporáneo, cuyo tratamiento deconstructivo posibilita señalar que el dolor, la frustración y el exilio han devenido liberación, ejercicio que proyecta una exploración sistemática y particularmente intensa de las distintas configuraciones de los seres humanos, en un contexto donde las categorizaciones morales han sucumbido y en que las distintas alteridades han ido buscando y asentándose, provisoriamente, en los espacios liberados por la estructuras estatales. En su trabajo narrativo/poético, es posible observar cómo desconsuelo, incomprensión, delirio, fantasía y angustia van sincopándose rítmicamente dejando salir e inscribiendo en sus textos un discurso extravagante, curioso y complejo en que las restricciones genéricas y convencionales de cualquier índole suelen ser superadas por las distintas intensidades que emanan de la escritura.

Con su abrupta salida de Uruguay en 1972, comienza un viaje en que el acto de desplazarse se transforma en un espacio movedizo y provisorio desde donde se instala, resiste y comienza su ardua búsqueda de la libertad, la justicia, la democracia y la igualdad, manifestaciones todas de ese pueblo al que le falta capacidad de reconstruirse con las armas secretas de la literatura, del lenguaje, de la poesía. "En el exilio su obra va desarrollando un concepto de la escritura cada vez más rico, más lírico, más consciente del valor y la función del lenguaje..." (Olivera-Williams 1986: 81). En este sentido, La nave de los locos $(1984)^{2}$ se erige como uno de los grandes hitos de su escritura narrativa, aun cuando su recepción haya sido tibia, producto de la extrañeza de esta novela cuyo tema es el viaje al exilio y la locura. La misma autora en "Literatura en libertad" ${ }^{3}$ señala: “... y soy consciente de que algunos de mis libros, cuando se publicaron en España, estaban muy adelantados a lo que era el lector español o la lectora española, pero yo los publiqué igual. Mi novela La nave de los locos, por ejemplo, es una gran alegoría sobre el exilio, y cuando la edité en 1984, en España la gente no estaba preparada para ese libro. En América Latina quizás tampoco. Eso es algo con lo que se tiene que

1 Los primeros años de la década del 70 en Uruguay fueron testigos de un cambio radical en la forma de concebir el desarrollo y futuro de la nación. Juan María Bordaberry, presidente democráticamente elegido en 1971, se transforma en dictador al encabezar el golpe de Estado del 27 de junio de 1973 para luego disolver el Parlamento, las organizaciones sociales y partidos políticos, coartando sistemáticamente las libertades civiles.

2 Todas las citas corresponden a: Peri Rossi, C. (1984). La nave de los locos. Barcelona, Seix Barral.

3 Entrevista con Ulrike Prinz (2008), recogida en http://www.cristinaperirossi.es/entrev.htm 
vivir. La sensación de precocidad o de estar adelantado. Kafka tiene un aforismo precioso que dice que la literatura es un reloj que adelanta. A veces atrasa, pero en mi caso adelanta" (online).

Desde su primer libro, Viviendo (1963), es posible rastrear la pesadumbre y el fracaso de proyectos colectivos del hombre contemporáneo, convulsionado por difíciles experiencias globales y conflictivos escenarios locales. Sus colecciones de relato, Los museos abandonados (1968) e Indicios pánicos (1970), junto a su primera novela, El libro de mis primos (1969), pasando por La rebelión de los niños (1980) y El museo de los esfuerzos inútiles (1983), van conformando una suerte de imaginario del fracaso y la frustración. Por lo tanto, su escritura necesaria y forzosamente va construyéndose dando la espalda al realismo mimético, dando paso a una lengua dislocada y fragmentaria, cercana al surrealismo, con lo cual desarticula a la vez que exhibe los dispositivos de dominación instalados en el organismo social de que forma parte tanto el autor como la obra que en adelante se presenta como contrahistórica o alternativa.

Su trabajo con la alegoría en diálogo con múltiples formas de exilio, cuestión por lo demás presente desde Virgilio (Prinz, online), singulariza su escritura culta, extremadamente erudita por momentos y atravesada por un vitalismo contrastante con el despliege narrativo en que se nos exhiben los distintos escenarios del dolor.

La fragmentación constante, como eje organizador de la escritura de Peri Rossi, privilegia la perspectiva dinamizadora de un discurso que en ese mismo ejercicio se va construyendo a sí mismo, va generándose como una factoría. En el momento en que se fractura el torrente discursivo, se cortan las intensidades del mismo, los cuales toman rumbos distintos que desestabilizan tanto el relato como al lector. En este sentido, es sumamente coherente que esta escritura relativice los fundamentos o estrías bases de la construcción mayor en que se inserta la obra. En La nave de los locos, la realidad adviene como una suma de marginalidades que la novela registra pacientemente, con el fin de enseñar y revelar la diferencia, los rostros otros y nuestro encuentro con ellos, mostrando las alteridades que se han forjado a partir de la segregación, exclusión y expulsión que los poderosos han realizado, fundamentalmente porque los han percibido como peligrosos y, por tanto, indeseables. En este sentido, coincidimos con Mónica Szurmuk (2003), quien postula que el recurso del exilio es utilizado en la novela para desnudar otros exilios (91, ss) que adoptan nombres tales como: mujer, niño, homosexual, judío, novelista. 
No obstante, el exilio en La nave de los locos va mutando desde la concepción de la marginación como puro despojo y negatividad, a la del éxodo como instancia de liberación, y, por tanto de superación de las categorizaciones propuestas por el poder. Hipótesis fundamental si recordamos que la misma escritora uruguaya ha declarado que el exilio fue "la experiencia más dolorosa de mi vida y también la más enriquecedora" (Strejilevich 40).

El carácter desestabilizador de la escritura de Cristina Peri Rossi, su intensidad desmitificadora (Verani, 1982) y su capacidad deconstructiva proyectan un relato extraordinariamente lúcido, a la vez que complejo, capaz de interpelar las zonas más íntimas y resguardadas del lector, quien logra percibir la crudeza, ingenuidad y perversidad de las relaciones humanas en sociedad, de tal modo que la novela se justifica como un dispositivo de conocimiento y exploración de la realidad desestabilizada y escindida, incapaz de reconocer la existencia en común de los distintos rostros alternos.

En este sentido, la novela reproduce ${ }^{4}$, en su construcción, aquella vital y compleja forma de vincularse entre los distintos actores sociales como entre los distintos y alternativos detentadores del poder, cuyos roles y esquemas de funcionamiento normativo han colapsado y provocado una crisis general en su lengua. La falta de estabilidad formal del relato aparece, en principio, por la casi nula progresión en el tratamiento de la fábula, la multiplicidad de foco, las múltiples referencias a otros textos, constantes desplazamientos del interés y digresiones varias. Lucía Invernizzi en "Entre el tapiz de la expulsión del paraíso y el tapiz de la creación: múltiples sentidos del viaje a bordo de La nave de los locos de Cristina Peri Rossi" (1987), logra percibir el texto como factoría en el nivel que lo proponemos: "A bordo de la nave, tanto el que escribe y enuncia como el que lee son navegantes, viajeros y coparticipan en la tarea de "inventar" el mar, de construir el texto" (49). El complejo escenario propuesto por la novela y las alianzas desproporcionadamente eruditas, obligan al lector a prepararse para ingresar a un territorio virtual en que es necesario ensamblar una historia, un discurso, una escritura. ${ }^{5}$

4 No podemos olvidar la categórica proposición de Michel Zéraffa en Novela y sociedad (1973) cuando advierte que "el escritor no inventa la técnica, y menos aún si se trata de la técnica novelística: la deduce de la realidad" (128). Es entonces la realidad la que se impone los términos del ejercicio y creación novelesca.

5 A propósito de lo expuesto, el prestigioso crítico uruguayo Fernando Aínsa en Nuevas fronteras de la narrativa uruguaya 1960-1993 (1986) apunta que la obra de Peri Rossi se ha construido sistemáticamente sobre un complejo tejido de transtextualidades: "Lejos de "flirtear" consciente

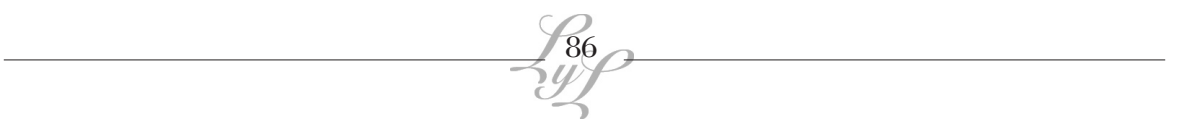


A continuación, trabajaremos la indefinición sexual de Equis, a partir de su relación con diversos tipos femeninos que van delineando su elección del entre lugar sexual.

\section{Las mujeres de Equis}

La primera es la Bella Pasajera, personaje, al igual que él sin nombre "otro", sin nombre sustantivo, sino adjetivo. Ambos se encuentran a bordo de la misma embarcación, lugar en que comienzan a provocarse sensualmente. Pasado un tiempo de seducción, deciden consumar esta incipiente relación con un encuentro sexual mediatizado por la imagen del juego de ajedrez, del cual evocan características como rigidez, estrategia, cálculo y, por supuesto, la posibilidad, mediada por la inteligencia, de ganar o perder e incluso empatar el lance:

La Bella Pasajera, paseando por la borda su languidez vestida de verde, su falsa curiosidad que condujera, inevitablemente, al camarote oscuro; bailando, a la noche, con la gracia medida y la incitación justa un lento bolero de Los Panchos (11-12).

El encuentro sexual es satisfactorio, cumple su función y ambos cuerpos, de la misma manera, ejecutan las tareas tradicionales en esta esfera. El deseo, entonces, se encuentra disciplinado y orientado a la ocupación puramente mecánica en que los "amantes" (etimología: los que están amando) repiten un rol preestablecido, anterior a cualquier subversión del mismo. Recordemos que lo único que conocemos de la Bella Pasajera es su apariencia física: "Ojos verdes y ancho mar. Caderas semovientes, amplios costillares" (11). La percepción de la mujer se encuentra dada desde la tradicional imagen del objeto sexual instrumental del placer y del deber masculino para con ella. Hasta el momento, Equis percibe a la mujer como objeto. Se lo pasa sentado en una butaca del cine Rex viendo filmes de Julie Christie, para contemplar las cualidades definitorias de su sexo, las que le provocan un evidente estado de excitación:

Transpira por los bellos ojos de Julie Christie, en los que el miedo aletea como un pájaro enjaulado; por los cabellos de Julie

y amablemente con el "pedantismo", como decían los enemigos de Borges, la narrativa de Peri Rossi invita a una parafernalia de palimpsestos, esa literatura en segundo grado, arquitextualidad, literalidad de la literatura, que nos da una intertextualidad plena de alusiones, de citas directas o más o menos disimuladas" (62). 
Indefinición sexual y disciplinamiento de un personaje Equis / Juan Cid Hidalgo

Christie que comienzan a despeinarse; por las piernas de Julie Christie que buscan, afanosas, un camino de salida; por su pelo rubio, por su boca carnosa, por sus senos firmes, por sus brazos torneados... (23).

El profundo deseo proyecta a Equis en la pantalla, donde quisiera estar para poseer a la bella actriz y salvarla de la máquina que destruye la habitación, en la escena que observa absorto, donde el mecanismo destructor asume como equivalente la masculinidad que él mismo encarna, motor que destrozaría cualquier intento de insurrección de otras voces, de otras intensidades, de otros discursos.

Contrasta, con esta hermosa mujer, la aparición de la vieja dama con quien Equis mantiene su segundo encuentro sexual. La oposición queda en evidencia con la descripción que se hace de ella y la similitud con un "ángel caído", un ángel robustecido por el placer:

Era una vieja dama rubia y gruesa, de tez muy blanca, labios delgados y ojos claros, pequeños, rodeados de pestañas largas y sedosas. A pesar de la edad, de los años que había acumulado grasa en ambos lados del cuerpo, dándole esa apariencia compacta, rotunda, Equis adivinó la tibieza de esa gordura... Lo que más maravillaba a Equis de la dama era el rostro de querubín envejecido, de ángel que ha engordado entre los placeres de la gracia (76).

La vecindad de este episodio con el campo semántico del cristianismo nos lleva a reconocer, en otros niveles, el espesor del texto de Cristina Peri Rossi. Equis, en el tiempo de la escritura, cuenta con treinta y tres años, vale decir, la edad de Cristo al morir o, más bien, de su paso por la muerte para llegar a otro estado, un estado de gracia que posibilita la salvación de todos los hombres. Leemos en El viaje, XII: el ángel caído: "Ella le sonrío y Equis pensó venturosamente que por lo menos le llevaba treinta y cinco años, es decir, que cuando él tuvo -sí: una vez tuvo- quince años, ella ya tenía cincuenta. Ahora debería tener por lo menos sesenta y ocho" (78).

Desde el título del capítulo se nos preorienta hacia los dominios de la fe, los terrenos "santos", aquellos en que la idea de pasión queda plasmada en el binarismo pasión teológica/pasión sexual que tradicionalmente han mantenido una tensión y una disputa que finalmente es zanjada por la adopción de uno u otro extremo de la disyunción. No obstante, al texto de Peri Rossi no le interesa resolver esta tensión, sino despojarla de sus límites; en definitiva, terminar con la segregación a partir del acto sexual, 
de la entrega sin prejuicios y preconcepciones, desinteresadamente, creadoramente. Con el acto sexual de Equis y la vieja dama, se funde el binarismo expuesto, ambas esferas: la carne y el espíritu, tradicionalmente pensados como polos apuestos, se disuelven en el pacto narrativo, cuestión impensable en un contexto que no sea el de la ficción.

Graciela, la próxima mujer, es una quinceañera testigo del episodio entre Equis y la vieja dama angelical, presencia que la instala de inmediato como oponente directa de la vieja. Esta, como dijimos, signada por su candorosa figura propia del cristianismo, contrasta con la mujer adolescente, descrita como un animal que la tradición ha cargado de erotismo: la yegua ${ }^{6}$. El carácter animal de Graciela, el poder de su sexo, la provocación y la sensualidad difieren con la severa dignidad e inteligencia con que aparece Equis a su lado:

Se podrá ser más inteligente -quizá-, pensó Equis. Más sensible o dúctil. Pero es seguro que no se puede ser un animal más espléndido. Cuando ella se sentó frente a él (sin excusarse ni temor a interrumpir), Equis estuvo a punto de relinchar. Pero era un hombre civilizado, un ser social, reprimido, acostumbrado a domar sus impulsos, como este otro potro (una sana y robusta yegua salvaje) no debía ser (86).

El proceso de disciplinamiento de que fue objeto el varón entra en crisis y aquellas certezas, cargadas en su configuración masculina, comienzan a fatigarse como el material sólido pierde su fortaleza, densidad y firmeza luego de un estremecimiento mayor: "Estuvo a punto de relinchar."

Esta niña/mujer, provocadora del deseo de la carne, desestabiliza la supuesta inteligencia del varón que tiene el dominio de las situaciones afectivas, desde el momento en que despliega su lucidez y determinación. Es ella quien toma la iniciativa y quien propone el encuentro sexual. La interrogación o petición "¿Lo harías conmigo?”, subraya el contraste de la joven con las anteriores mujeres, pues es ella quien toma las riendas del asunto y provoca el desconcierto de Equis en su rol masculino sustentador y disciplinador, tanto intelectual como económicamente, de las mujeres, esos seres "incompletos". En El viaje, XIII: la isla, nos enteramos de la osadía de Graciela, la perturbadora:

6 Cómo olvidar el hermoso texto de Mario Vargas Llosa El elogio de la madrastra (1988) en que la "grupa" de yegua de Lucrecia llena de sensualidad el relato plástico y narrativo de esta breve novela erótica. 
-No me gusta sintonizar la voz de la experiencia -protestó Graciela-. Voy a perder mi examen de lógica. De todos modos, lo que pienso lo he pensado sola -agregó, sombría-. Nadie me ha preparado para esto. ¿Tienes preservativos?

Equis volvió a sobresaltarse y contestó que no.

-Me lo imaginaba -suspiró ella-. ¿Eres de los que pretenden que una se arruine la salud tomando píldoras o abortando en una clínica sólo-para-mujeres? ¿O acaso haces el amor nada más que con viejas? (90-91).

La humillación máxima de Equis no llega a concretarse, el narrador solamente deja entrever que Graciela lo lleva a una cueva rodeada de rocas donde se consumaría el encuentro sexual. La intensa influencia de Graciela sobre Equis dará pronto sus frutos en la constitución de su indefinición sexual, superación de las categorías sexuales y de sus disciplinamientos particulares.

\section{Indefinición sexual, camino a la androginia}

Las marcas del progresivo camino a la indefinición sexual del personaje se van acumulando a medida que vamos conociendo las distintas relaciones que va manteniendo con variadas mujeres, de cuyas experiencias fue inscribiendo en sí solamente aquellas determinantes para su elección posterior. Sin embargo, la elección del entre lugar sexual se consuma en un episodio que cifra ejemplarmente esta problemática, por cierto, recurrente en la narrativa de Cristina Peri Rossi.

Lucía es un personaje femenino que se vuelve andrógino ${ }^{7}$. Equis la conoce como mujer cuando la acompaña, como parte de su trabajo, en un largo viaje en bus a una clínica de abortos, donde induce la muerte del ser en su vientre, en condiciones tan duras como humillantes y que la hacen renegar de su condición de mujer cuando jura que no volverá a tener relaciones íntimas con un hombre. Pasado un lapso la vuelve a

7 "Dicho de una persona cuyos rasgos externos no se corresponden definidamente con los propios de su sexo" dirá la RAE, a lo que hay que agregar la locución latina coincidentia oppositorum con lo que se quiere explicar la mezcla ambigua de lo masculino y lo femenino cifrado en un sólo sujeto. Recomendamos, a propósito de esta temática, la lectura de "La presencia del mito de andrógino en La nave de los locos de Cristina Peri Rossi" de Cristina Valdivia, seminario para optar al grado de Licenciado en Lengua y Literatura Hispanoamericana de la Universidad de Chile. 2003. Disponible en http://www.cybertesis.cl/tesis/uchile/2003/valdivia_c/html/indexframes.html

190


encontrar en un club de bailes eróticos, lugar en que se entera de que la mujer que conoció ahora es un "hermoso efebo":

Un hermoso efebo el que miraba a Equis y se sintió subyugado por la ambigüedad. Descubría y se desarrollaban para él, en todo su esplendor, dos mundos simultáneos, dos llamadas distintas, dos mensajes, dos indumentarias, dos percepciones, dos discursos, pero indisolublemente ligados de modo que el predominio de uno hubiera provocado la extinción de los dos (195).

En este club, Lucía baila y actúa con una pareja varón. Ella asume el papel de Dolores del Río y su pareja la de Marlene Dietrich ${ }^{8}$. Con el ingreso de Equis al espacio del deseo asume la especificidad del lugar y sus normas de funcionamiento. La actividad de exhibirse en un local de striptease, entonces, conlleva la aceptación de cierto código de acción propio de estos lugares en que se libera el deseo sexual. Equis, al reconocer a Lucía, la describe asimilándola a personajes femeninos de películas, enfatizándose que estamos ante una escena de imitación de la imitación o imitación en tercer grado ya que Lucía imita a Charlotte Rampling en Portero de noche (Cavani, 1974), quien a su vez imitaba a Helmut Berger en La caída de los dioses (Visconti, 1969) ${ }^{9}$. Como vemos, el travestismo tradicional no es precisamente la acción perturbadora, es en otro nivel en que está puesto el interés de esta escena de suplantación de persona-

8 Dolores Asúnsolo y López Negrete del Río (1904-1983) fue una reconocida actriz de cine mexicano en los tiempos del cine mudo hollywoodense. Es considerada como una de las grandes divas y figura mítica del mundo del espectáculo de su país a mediados de siglo XX. Desde muy joven presentó facilidad para aprender parlamentos, además de una enorme afición por el baile. Precisamente en un baile benéfico, a eso de los 15 años, conoce a quien sería su primer esposo, un destacado, culto y prominente caballero de la sociedad mexicana, Jaime Martínez del Río de quien toma el apellido que la llevaría a la celebridad. A su llegada a Hollywood fue considerada la versión femenina de Rodolfo Valentino. En tanto, Marie Magdalene von Losch llamada Marlene Dietrich (1901-1992) fue una actriz y cantante alemana de nacimiento y estadounidense por adopción. Famosa por su pulcra apariencia, su buen vestir (impuso la moda del pantalón femenino) y su imagen de femme fatale, fue icono de la elegancia y el glamour, en el incipiente jet set de Hollywood. Aunque el gran amor de la actriz fue el actor y héroe militar francés Jean Gabin, conocidas eran sus apetencias sexuales lésbicas, hechas públicas por su propia hija María Sieber (Riva después de casada) en Marlene Dietrich por su hija, Maria Riva. Algunos romances que se le imputan llevan el nombre de afamadas mujeres del espectáculo: Mercedes de Acosta, Claudette Colbert, Greta Garbo y María Félix habrían sido algunos de sus amores. Su condición bisexual queda de manifiesto además por sus variados amoríos con hombres en su desprecio de la actividad sexual, a decir de su hija la práctica sexual nunca gustó del todo a su madre.

9 "Alcanzó a ver, en un número de conjunto a Lucía, vestida de varón, con chistera (sobre sus cortos cabellos rubios), corbata y pantalones anchos, que flotaban, imitando a Charlotte Ramplig en Portero de noche, quien imitaba a Helmut Berger en La caída de los dioses, quien imitaba a Marlene Dietrich en El ángel azul. Siendo, entonces, Marlene Dietrich, el origen y desenlace de toda simulación" (191). 
lidades por medio de la actuación y el baile. La exhibición frente a un público heterogéneo de varones, la puesta en escena de la estimulación muda y recíproca entre Dolores y Marlene -quienes se valen del público para acrecentar su propio erotismo, despreocupándose de quienes deben ser los estimulados, o provocados por esta "ficción"- desestiman el rol tradicional de su trabajo, es decir, excitar y recrear en el terreno sexual a los consumidores de sexo. Ellas se prodigan mutuamente a la vez que menosprecian a los consumidores/espectadores del espectáculo, quienes, según el pacto implícito del emplazamiento, acuden a mirar y no a tocar, por lo tanto, su vivencia en el lugar tiene como objetivo exacerbar su erotismo a través del acto de mirar (voyeur) desde su condición de género superior. Sin embargo, el deseo es tan fuerte que, desde el mismo lugar señalado, intenta sobrepasar los límites, acto que autoriza a su contraparte a actuar de la misma forma. "Varios se ofrecían para ayudarla, pero Dolores, brava chicana, defendía el territorio, Dolores no iba a permitirlo, el precio es por ver y no por tocar, queridito mío, qué te has creído tú, hijo o hija de tu madre..." (192).

Con esta última y provocadora afirmación, se pone en cuestión la importancia del deseo en la configuración del rol masculino y femenino. Al parecer, es el deseo profundo el que provoca la caída del binarismo de género. Cuando los varones intentan traspasar los límites de la ficción del streaptease ¿lo que desean es ser parte de esa ficción (dos mujeres transvestidas estimulándose) desde su masculinidad?, o, más bien, ¿desean sentir como mujeres que han decidido estimularse entre ellas, aun cuando cubran su cuerpo con prendas masculinas? Creemos que lo importante no es la resolución de estas interrogaciones, sino más bien que el deseo alisa el binarismo, lo desarticula de tal modo que desde el lenguaje (código normalizador y disciplinador por antonomasia) ya no es posible discriminar a unos de otros: "hijo o hija de tu madre" señalan los/as artistas cuando los varones/as intentan "sobrepasarse".

En esto se ha transformado Lucía, en un sujeto que transgrede incluso el binarismo de identidad sexual ${ }^{10}$. No es ni lo uno ni el otro, es ambos

10 Amy Kaminsky en "Cristina Peri Rossi and the Question of Lesbian Precense" texto publicado en Reading the Body Politics. Feminist Criticism and Latin American Women Writers (1993) se refiere a esta proposición como sigue: "Al usar tropos y convenciones existentes, y al escribir sobre las mujeres como objetos sexualmente deseables, Peri Rossi (...) cuestiona tanto la universalidad de la heterosexualidad como la noción de texto independiente. Los significados cambian cuando el género del autor es conocido. Incluso (o quizá especialmente) cuando ella usa un personaje masculino, el efecto de su poema erótico sobre una mujer es opuesto al de un hombre. Mientras que el poema de un hombre reinscribe y refuerza las tradicionales relaciones de género y las nociones tradicionales de sexualidad, los suyos las cuestionan. Mientras que el poema de

$\longrightarrow$


a la vez. La performance teatral de las dos mujeres y su exhibición nos parece un acontecimiento rebelde que "intenta encarnar la posibilidad de una identidad alternativa y liberarse a sí mismos a través de la actuación ambigua, pero también poner de manifiesto la ambigüedad sexual de su audiencia" (Fonder, 2003). En este sentido, creemos que la actuación, el acto de ficcionalización de Marlene y Dolores, representa precisamente lo que son los papeles sexuales en las sociedades modernas: roles y parlamentos fijos reproducidos hasta la saciedad. Esta definición del género sexual se proyecta, entonces, como una forma de disciplinamiento que deja fuera de su lógica a aquellos sujetos instalados en el "entre".

Los espectadores del "show" de Dolores y Marlene, aquellos disciplinados en forma conveniente, aparecen caricaturizados grotescamente. Leemos en El viaje, XXI, capítulo final de la novela y cifra de la mayoría de edad.

Arrellenados en sus asientos, con esa falsa seguridad que les daba el ser muchos y anónimos, haber pagado la entrada, estar abajo y no arriba, tener el abdomen con grasa, el aliento pesado, el chiste fácil y un músculo reflejo entre las piernas, los espectadores parecían haber retrocedido a algún estadio de impunidad infantil, en el cual se sentían dominadores, desinhibidos, irresponsables.

El anonimato y el sentimiento de formar parte de un mismo grupo (no había casi mujeres en la sala) estimulaba una conducta provocativa, obscena, falsamente ingeniosa. Se oían chistes, burlas, réplicas, bolsas llenas de aire que estallaban, largos eructos, silbidos, aplausos y pataleos (190).

Estos voyeurs, desde el momento en que deciden pagar e ingresar a un local erótico, lo hacen desde la autoafirmación de su masculinidad -que posibilita, como sujetos disciplinados que son, ingresar sin temor a poner en tela de juicio su "normalidad"- y reaccionan precisamente ejerciendo el poder que su estado de normalidad/superioridad convoca en casos de trasgresión de los límites de la moral y las buenas costumbres. Reaccionan de la manera más primitiva y ancestral, con palabras sueltas, eructos, aplausos y pataleos. En este sentido, entonces, los exhibidos no son las artistas quienes están "actuando" sobre el escenario,

un hombre apoya la idea de que el poeta/sabedor/hablante es masculino y esta masculinidad es natural y unitaria, con la fácil coincidencia de poeta masculino y hablante masculino, el despliegue de un personaje masculino en los poemas de Peri Rossi altera y desestabiliza las asunciones recibidas" (121). 
sino los espectadores que están "viviendo" bajo él, aquellos que, en el intento de ridiculización de esas mujeres/hombre lo que están logrando es ridiculizarse a sí mismos ${ }^{11}$.

La caída de los lindes de la identidad sexual binaria se amplifica en numerosos binarismos que se van deconstruyendo en el texto, ejercicio que va alisando el territorio para conformar una sola zona de intensidades. La amplificación sugerida desintegra los binarismos: espectador/ espectáculo, oscuro/iluminado, escondido/exhibido, anónimo/identificado. El primero se fractura, como dijimos, en el momento en que los "normales", la masa de hombres alrededor de las actrices, queda en ridículo por lo grotesco de sus actitudes frente a los perturbadores. Quienes quedan como número tragicómico de circo son los espectadores que asumen ahora la zona iluminada del teatro, el centro donde ya no se pueden amparar en la oscuridad y el anonimato. Frente a otra categoría de ojos, capaces de ver y traspasar esas paredes territoriales, están siendo exhibidos en una dimensión cercana a la animalidad, con lo que el lector, en este tercer grado de distanciamiento frente a lo proyectado, logra percibir la ignominia, la majadería y arrogancia de esos sujetos disciplinados en el plano sexual y descalificadores de la diferencia.

La ridiculez de los espectadores parodiados en esta escena, lo artificial y esquematizado de su masculinidad, contrastan a la perfección con la trasparencia y autenticidad del trabajo artístico de Dolores (Lucía). El narrador parece así sentir simpatía por el personaje travestido:

Un hombre disfrazado de mujer, o una mujer, un travesti, uno que había cambiado sus señas de identidad para asumir la de sus fantasías, alguien que se había decidido a ser quien quería ser y no quien estaba determinado a ser (191).

El disciplinamiento fallido da paso a la propia autoafirmación de la diferencia, a través de una decisión libre, soberana y responsable. El narrador, que ha tomado partido por la ambigüedad e idealizado la performance de Marlene y Dolores, ha cuidado sus dichos para no "manchar" ni contaminar el momento de superación del binarismo. Equis, el viajero infatigable, al presenciar el espectáculo de los sujetos amparados en la oscuridad y el anonimato, señala que "hasta los brutos son sensibles a la ceremonia de sus manos" (192), denotando con ello la

11 En "Soñar para seducir", entrevista de Elena Golano (1982), la novelista apunta: "crea una tensión entre la multiplicidad de ser y las exigencias sociales: no hay nada más ridículo que un hombre que se cree muy hombre; esto es siempre una simplificación, una reducción." (50).

194


nula sensibilidad de este grupo de disciplinados, incapaces de apreciar la belleza, la seducción otra, el deseo otro. De cierto modo, no son capaces de despojarse de las normas y convencionalismos que en el plano de la sexualidad los han dejado "castrados". Al igual que en el episodio de Percibal y Morris, debemos recordar, siguiendo a Foucault en El uso de los placeres, que es el "apetito natural" por la belleza lo que supera las diferencias de sexo y edad en la constitución del deseo:

A sus ojos, lo que hacía que se pudiera desear a un hombre o a una mujer era solamente el apetito que la naturaleza había implantado en el corazón del hombre hacia quienes son "bellos", cualquiera que fuera su sexo (Foucault, 2003: 173).

Los espectadores, entonces, con sus masculinos ojos y su altanera virilidad no logran percibir aquellas dimensiones en que el placer transita por los cuerpos sin distinciones. Finalizada la performance, Equis va tras bambalinas a buscar a Lucía. En este momento, se produce un nuevo acontecimiento trasgresor, ahora experimentado por el personaje central de la novela, quien se siente perplejo al darse cuenta de que su presencia en el lugar no provoca reacción alguna. "Equis quedó de pie, junto a la puerta, con la penosa sensación de que las mujeres lo miraban sin curiosidad, sin sorpresa, como si fuera un objeto. Una mesa o un ropero junto a la puerta, obstaculizando el paso" (195). La superación del binarismo de oposición sexual es tal que se siente invisible, sin sus cualidades de sujeto particular vivo y en constante adecuación para relacionarse con otros sujetos igualmente disciplinados. Alguna crítica dirá que esta imagen de los actores andróginos, que no "sienten" ninguna atracción ni interés por Equis, es una señal de la autosuficiencia de los sujetos alternos sexuales, y que la percepción de los otros como muebles y objetos se daría por constituirse estas imágenes como parte del orden patriarcal dominante. Nosotros, sin el ánimo de descalificar una apreciación en este sentido, creemos que el nivel de superación de este binarismo es de tal magnitud que se pierde la proporción del cambio, momento en el cual recordamos, con Michel Foucault, un peligro latente: "Mi posición es que no tenemos que proponer. Desde el momento en que se propone un vocabulario, una ideología, no puede tener sino efectos de dominación" (1994: 85).

\section{Conclusión}

En La nave de los locos, la expulsión consumada de los perturbadores del seno de la sociedad normalizadora, el exilio y la marginalidad de que 
son objeto personajes como Equis, la incógnita que permite el enroque por cualquier nombre sustantivo, exhibe el proceso de adecuación y sobrevivencia de estos sujetos al terror y el peregrinaje constante en busca de su tierra. La marginación como determinación histórica y cultural, el trabajo alrededor del tópico de la stultifera navis y la ascención de los disidentes a estadios superiores del binarismo sexual, solidifican el camino al reconocimiento del entre lugar sexual como instancia propicia para el encuentro entre hombres y mujeres, fuera de las categorías propias del lenguaje, aquel dispositivo que reduce cualquier intento de subversión y del cual no hemos podido desembazarnos en la exposición de este agenciamiento.

A partir de la androginia, entonces, se establece una coordenada para el encuentro entre los seres, un encuentro favorecido por el descubrimiento y experimentación con el deseo desbocado, anterior a cualquier convencionalismo o disciplinamiento rector de conciencias, tanto individuales como colectivas. A la luz de expuesto, la novela de la escritora uruguaya Cristina Peri Rossi nos demuestra que aún en el dolor es posible incubar la utopía.

\section{Bibliografía}

Aínsa, F. Nuevas fronteras de la narrativa uruguaya 1960-1993. Montevideo: Trilce. 1986.

Berguero, A. "'Yo me percibo como una escritora de la modernidad'. Una entrevista con Cristina Peri Rossi". Mester. 32 (1993): 67-87.

Blanco-Arenjo, M. "Un desafío para el lector: metamorfosis e identidad en La nave de los locos de Cristina Peri Rossi". Hispania. 80, 3 (1997): 441-450.

Cánepa, G. "Claves para una lectura de una novela de exilio: La nave de los locos de Cristina Peri Rossi". Anales. 1 (1989): 117-130.

Deleuze, G. y Guattari, F. Mil mesetas. Valencia: Pre-Textos. 1997.

Filc, J. "Espacios alterados: la calle y el hogar en tres novelas de la dictadura en el Río de la Plata". Revista Estudios interdisciplinarios de América Latina y el Caribe (EIAL). 12, 2, juliodiciembre (2001).

http://www.tau.ac.il/eial/XII_2/flic.html. Consultado 5 de junio de 2010. 
Fonder-Solano, L. "Erotismo, actuación y la construcción de identidad: La nave de los locos de Cristina Peri Rossi". Ciberletras Revista de Crítica Literaria y de Cultura, de Lehman Collage New York. 10 (2003).

http://www.lehman.cuny.edu/ciberletras/v10/fondersolano.htm. Consultado 25 de julio de 2010.

Foucault, M. Genealogía del racismo. Madrid: La Piqueta. 1992.

"Encierro, psiquiatría y prisión". Un diálogo sobre el poder y otras conversaciones. Madrid, Alianza. 1994.

Historia de la locura en la Época Clásica. México: Fondo de Cultura Económica. 1998.

Historia de la sexualidad. 1. la voluntad del saber. Buenos Aires: Siglo XXI. 2003.

Historia de la sexualidad. 2. El uso de los placeres. Buenos Aires: Siglo XXI. 2003.

Golano, E.: "Soñar para seducir". Quimera, No 25, (1982), 47-50.

Invernizzi, L. "Entre el tapiz de la expulsión y el tapiz de la creación: múltiples sentidos del viaje a bordo de La nave de los locos de Cristina Peri Rossi". Revista Chilena de Literatura. 30 (1987): 29-53.

Kaminsky, A. "Cristina Peri Rossi and the Question of Lesbian Presence". Reading the Body Politics. Feminist Criticism and Latin American Women Writers. Minneapolis/London: University of Minnesota Press. 1993.

Magnarelli, S. The Lost Rib: Female Characters in the Spanish-American Novel. Lewisburg: Bucknell University Press. 1985.

Mattalía, S. "Islas a la deriva, identidades flotantes: La nave de los locos de Cristina Peri Rossi". La isla posible: III Congreso de la Asociación Española de Estudios Literarios Hispanoamericanos. (2001): 359-364.

Olivera-Williams, M. "La nave de los locos" de Cristina Peri Rossi". En Revista de Crítica Literaria Latinoamericana. Año 12, No 23 (1986): 81-89.

Pereyra, M. "La alteridad y sus múltiples representaciones: el modo utópico como dinámica del deseo en La nave de los locos de Cristina Peri Rossi". MACLAS Middle Atlantic Council for Latin American Studies, Vol. XV (2001). http:// 
Indefinición sexual y disciplinamiento de un personaje Equis / Juan Cid Hidalgo

www.maclas.vcu.edu/journal/Vol\%20XVII/marisa.

htm. Consultado 3 septiembre de 2010.

Peri Rossi, C. La nave de los locos. Barcelona: Seix Barral. 1984.

Prinz, U. "Literatura es libertad. Entrevista a Cristina Peri Rossi. Barcelona (Dic. 2008)". En Revista Matices. Junio 2010: Reproducido en http://ww.cristinaperirossi.es/entrev. htm

Strejilevich, N. El arte de no olvidar. Literatura testimonial en Chile, Argentina y Uruguay entre los 80 y los 90. Buenos Aires, Catálogos. 2005. Disponible en http://www.norastrejilevich. com/images/ElArtedenoOlvidar.pdf. Consultado 19 octubre de 2010.

Szurmuk, M. "Extranjería y exilio en La nave de los locos de Cristina Peri Rossi”. El otro, el extranjero. Comp. Fanny BlanckCereijido y Pablo Yankelevich. Buenos Aires: Libros del Zorzal, (2003). 89-108.

Valdivia, C. "La presencia del mito de andrógino en La nave de los locos de Cristina Peri Rossi", seminario para optar al grado de Licenciado en Lengua y Literatura Hispanoamericana de la Universidad de Chile. (2003). Disponible en http://www.cybertesis.cl/tesis/uchile/2003/valdivia_c/ html/index-frames.html. Consultado 13 septiembre de 2010.

Verani, H. "Una experiencia de límites: la narrativa de Cristina Peri Rossi". Revista Iberoamericana, XLVIII, 118-119, (1982): 303-316.

Zéraffa, M. Novela y sociedad. Buenos Aires: Amorrortu Editores. 1973.

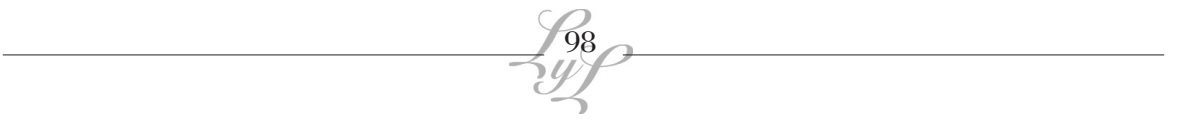

